\title{
Patient-reported outcomes and efficiency of complete dentures made with simplified methods: A meta-analysis
}

\section{Efektywność protez całkowitych wykonanych metodami uproszczonymi w opinii pacjentów - metaanaliza}

\author{
Asim Al-Ansari ${ }^{\mathrm{A}, \mathrm{B}, \mathrm{D}-\mathrm{F}}$, Maha El Tantawi ${ }^{\mathrm{B}-\mathrm{F}}$ \\ Department of Preventive Dental Sciences, College of Dentistry, Imam Abdulrahman Bin Faisal University, Dammam, Saudi Arabia \\ A - research concept and design; $\mathrm{B}$ - collection and/or assembly of data; $\mathrm{C}$ - data analysis and interpretation; \\ $D$ - writing the article; $E$ - critical revision of the article; $F$ - final approval of the article
}

\section{Address for correspondence \\ Maha El Tantawi \\ E-mail: maha_tantawy@hotmail.com}

\section{Funding sources}

None declared

Conflict of interest

None declared

Received on April 17, 2019

Reviewed on May 16, 2019

Accepted on June 9, 2019

Published online on December 30, 2019

Cite as

Al-Ansari A, El Tantawi M. Patient-reported outcomes and efficiency of complete dentures made with simplified methods: A meta-analysis. Dent Med Probl. 2019;56(4):411-418. doi:10.17219/dmp/109945

DOI

$10.17219 / \mathrm{dmp} / 109945$

Copyright

๑) 2019 by Wroclaw Medical University

This is an article distributed under the terms of the

Creative Commons Attribution 3.0 Unported License (CC BY 3.0)

(https://creativecommons.org/licenses/by/3.0/)

\begin{abstract}
Background. An increasing lifetime expectancy of the elderly highlights the importance of prosthodontic techniques, such as preparing complete dentures, which can restore the complete loss of teeth.

Objectives. The present study compared patient-reported outcomes and efficiency in terms of preparation time and cost of a simplified complete denture (SCD) and a conventional complete denture (CCD) in edentulous patients using a meta-analysis of clinical trials (CTS).
\end{abstract}

Material and methods. A literature search was conducted for studies comparing SCD and CCD in MEDLINE (PubMed), Scopus and World of Science, and through analyzing the reference lists of the retrieved studies, without language or time limits. Studies fitting the pre-specified inclusion criteria were assessed for quality and the extracted data referred to the following issues: patient satisfaction measured using a 100-millimeter visual analog scale (VAS); impact on quality of life estimated using the Oral Health Impact Profile (OHIP)-19 on a scale from 0 to 38; the proportion of cost of $S C D$ to $C C D$; and time in minutes to deliver dentures. The results were pooled in meta-analyses and displayed in forest plots.

Results. Eleven publications referring to 7 studies were included in the meta-analysis. There were no differences between SCD and CCD in patient satisfaction (mean difference: $0.896,95 \% \mathrm{CI}$ (confidence interval): $-2.947,4.739$ ) or their impact on quality of life (mean difference: $0.379,95 \% \mathrm{Cl}:-0.994,1.751$ ). It required significantly less time to deliver SCD (mean difference: $-274.16,95 \% \mathrm{Cl}$ : $-348.37,-199.96)$ and it cost significantly less (proportion: $0.740,95 \%$ Cl: $0.597,0.882)$. Both SCD and CCD similarly impacted the patient's quality of life and satisfaction. It took about $4.5 \mathrm{~h}$ less to deliver SCD to patients as compared to $C C D$ and the cost of SCD was $75 \%$ of the cost of CCD.

Conclusions. Compared to CCD, SCD had a similar impact in terms of satisfaction and quality of life with reduced treatment time and cost. More studies are needed in low-resource settings, where SCD may have a greater advantage.

Key words: complete dentures, Health-Related Quality of Life, patient comfort, dental services

Słowa kluczowe: protezy całkowite, jakość życia uwarunkowana stanem zdrowia, komfort pacjenta, usługi dentystyczne 


\section{Introduction}

With life expectancy increasing worldwide, ${ }^{1}$ more individuals reach the state of complete edentulousness, and therefore need prosthodontic rehabilitation. Despite the presence of a variety of prosthodontic modalities, complete dentures remain the most widely used solution. ${ }^{2}$ In many parts of the world, the cost of complete dentures may be prohibitive, depriving those in need of rehabilitative services, which affects their quality of life and wellbeing. ${ }^{3}$ Several studies have been conducted to assess the usefulness of a simplified complete denture (SCD) as a less costly alternative to a conventional complete denture (CCD). ${ }^{4-7}$ A simplified complete denture is defined as a complete denture which is fabricated in less time compared to CCD through the omission of some steps during impression making, occlusal registration or try-in. ${ }^{3}$ Two systematic reviews compared these 2 types of dentures regarding patient-reported outcomes, in addition to cost and time. ${ }^{3,8}$ Neither of them provided an overall estimate of the differences between the 2 types of dentures with respect to these features. Several studies ${ }^{6,7,9,10}$ have been conducted since the publication of the most recent of these 2 systematic reviews. ${ }^{3}$

The present study updates the information reported in the 2 previous systematic reviews and conducts a metaanalysis of the differences between both types of dentures. The aim of this systematic review and meta-analysis was to answer the PICO question whether there is a difference between SCD and CCD in terms of patient satisfaction, their impact on quality of life, their cost, and time needed to deliver the dentures.

\section{Material and methods}

\section{Inclusion criteria}

In this meta-analysis, the following inclusion criteria were adopted: studies conducted on completely edentulous adult patients; studies assessing the use of SCD; CCD as control; controlled clinical trials (CTs), whether parallelgroup or crossover designs; studies assessing any or all of the following outcomes - patient satisfaction, impact on quality of life, cost, or time taken to provide the patient with a complete denture.

\section{Search strategy}

The MEDLINE (PubMed) database was searched using the Medical Subject Headings (MeSH) term 'denture, complete' combined using the Boolean operator AND with 'simplified'; no time or language limits were applied. The Scopus and World of Science databases were searched using the term 'simplified complete denture'. The reference lists of the retrieved articles were also searched.

\section{Study selection}

After the search, the titles and abstracts of the retrieved articles were scanned to assess if they fitted the inclusion criteria. If this could not be ascertained, full texts were scanned. The studies were excluded based on each criterion.

\section{Quality assessment}

The quality of the studies was assessed using the method described by Egger et al. ${ }^{11}$ The following issues were evaluated: randomization and allocation concealment, the sample size estimation method, reporting clear inclusion/ exclusion criteria, the completeness of follow-up, the comparability of groups at baseline, and the blinding of outcome assessors. These items were scored on a scale from 0 to 2 , with 0 indicating inadequate or absent information of a limited or no value as evidence, and 2 indicating clearly explained and adequate information of a high value as evidence. A total score was calculated for each study.

\section{Data extraction}

From the studies included in the present meta-analysis, the following data was extracted to describe the study features: the year of publication; the place where the study was conducted; the study design; the SCD preparation steps that differed from those for CCD; the number of participants in each group; and the participants' age, in addition to patient satisfaction, impact on quality of life, cost, and delivery time. In the included studies, satisfaction was measured on a visual analog scale (VAS) ranging from 0 to 100 , with higher scores indicating a greater satisfaction. In 1 study, satisfaction was measured on a scale ranging from 0 to 10 , so the scores were multiplied by 10 to be similar to those from other studies included in the meta-analysis. Impact on quality of life was assessed using the Oral Health Impact Profile (OHIP), which is a 19-item questionnaire. In some studies, answers to these questions were scored from 0 to 4 (5-point Likert scale) and in others from 0 to 2 (3-point Likert scale), resulting in a potential total score ranging from 0 to 76 or from 0 to 38 , respectively. Thus, this variable had different ranges. To produce similar scores to be used for the present meta-analysis, all values were transformed to scores ranging from 0 to 38 . The absolute cost comprised the personnel cost, which is the cost of time needed for the dentist to deliver the denture to the patient, and the cost of materials and equipment. The proportion between the cost of SCD and CCD was calculated using a previously reported method. ${ }^{12}$ The cost was also transformed to the USD value at the time of the study ${ }^{13}$ and corrected for inflation. ${ }^{14}$ In all studies, the time required to deliver the denture to the patient comprised the time for fabrication and the time for adjusting the denture to fit the patient's needs. 


\section{Analysis}

The analysis was conducted using the OpenMeta[Analyst] software. ${ }^{15}$ Theoutcome variables were measured on continuous scales as mean differences (except for cost, which was measured as a proportion) and confidence limits were calculated. For the meta-analysis, the similarity between the results was assessed using $I^{2}$. The random effects model was used if the results were heterogeneous. Forest plots were developed for each outcome. We used the Meta-Essentials tool (https:// www.erim.eur.nl/research-facilities/meta-essentials/) to draw a funnel plot and to calculate the $p$-value of Egger's test in order to assess publication bias. ${ }^{16}$

\section{Results}

The MEDLINE search generated 110 articles, of which only 18 were CTs. In Web of Science, the corresponding numbers were 213 articles, of which 20 were CTs, and Scopus generated 152 articles, of which 19 were CTs. All records were imported to the Mendeley reference management software (https://www.mendeley.com/download-desktop/) and after duplicates were removed, there were 27 articles left. Of these, 4 were excluded, because their study design did not fit the inclusion criteria; they were systematic reviews or clinical studies, not trials. Six were excluded, because they did not have either the intervention or the control specified in the inclusion criteria or both, or because the study took into consideration implant-supported prostheses. Two studies were excluded, because they were comments/summaries of another study. Four were excluded, because they did not assess the required outcomes. The remaining studies $(\mathrm{n}=11)$ were included in the analysis (Fig. 1 ).

The 11 papers included in the review described 7 studies (Table 1). There were 3 articles from Brazil, 1 from Chile, 3 from Canada, 1 from Germany, 1 from Italy, and 2 conducted in Japan.

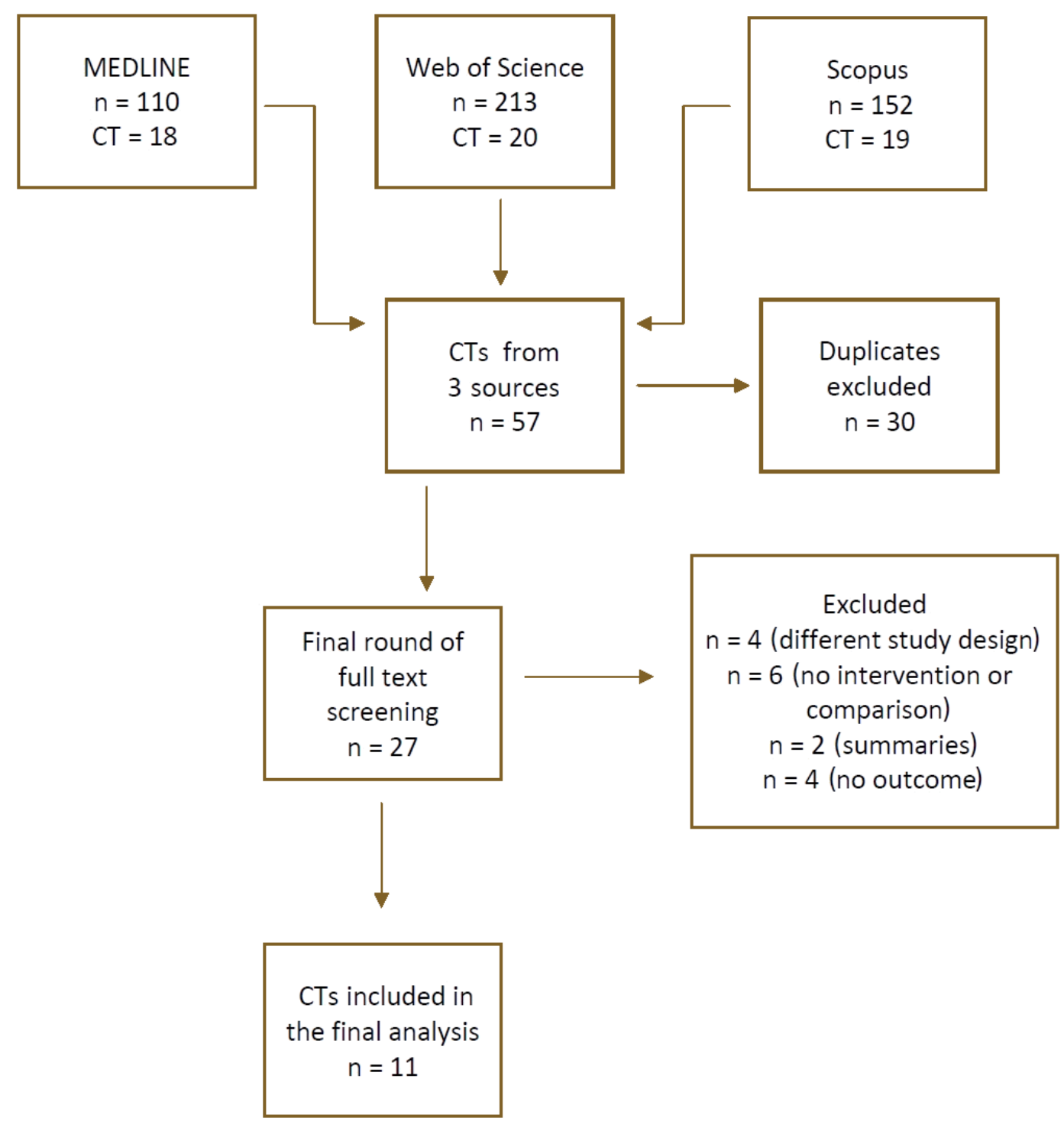

Fig. 1. Flow chart of clinical trials (CTs) included at different stages of the systematic review 


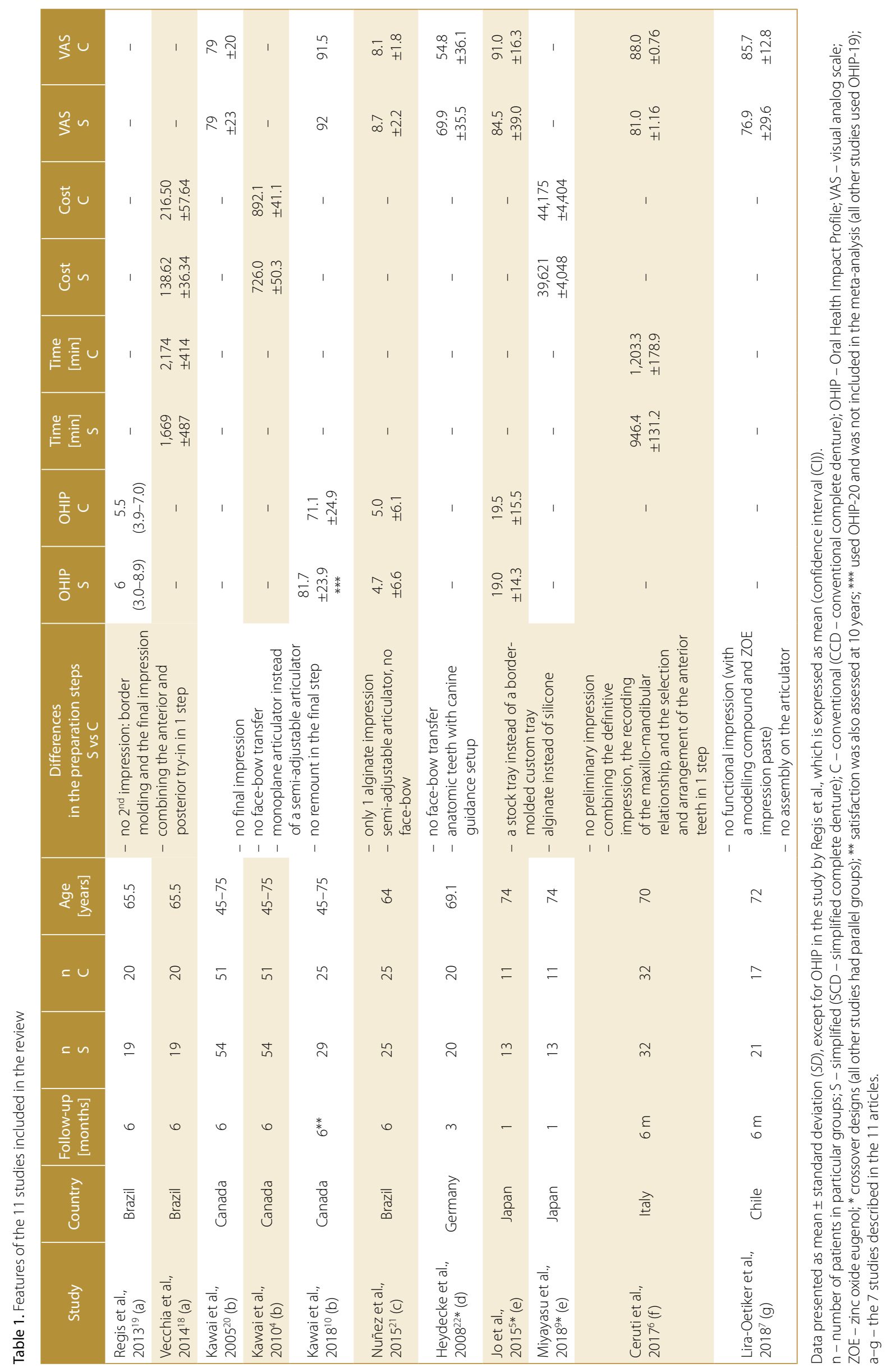


Three studies assessed impact on quality of life, 7 studies assessed patient satisfaction, 3 studies assessed cost, and 2 studies assessed time to deliver dentures to patients. Of these 7 studies that were included in the 11 papers, 2 were crossover studies and the remaining 5 included parallel groups. The total number of participants was 24-105. The follow-up period ranged from 1 month to 10 years. In most studies, the steps that were most frequently omitted in SCD preparation in relation to CCD were face-bow transfer and the final impression. The satisfaction estimates from 3 studies were not used in the meta-analysis, as 2 studies reported estimates after 1 month and 3 months, ${ }^{5,22}$ respectively, whereas in the $3^{\text {rd }}$ study (by Kawai et al. ${ }^{10}$ ), satisfaction was assessed after 6 months, but only for a subset of the sample of another study that was already included. In 1 study, impact on quality of life measured with OHIP-19 was assessed at 1 month and that study was not included in the meta-analysis. ${ }^{5}$

Table 2 shows that all 7 studies described in the 11 articles adequately explained the inclusion/exclusion criteria and reported that outcome assessors were blinded to the group the patients were allocated to. Patients were not informed of the differences between the 2 types of dentures so that their reporting on satisfaction and impact on quality of life could not be biased. All studies except 1 explained how the sample size was estimated and detailed the underlying assumptions. Two studies did not explicitly show the number of participants available at follow-up, and 3 studies did not show differences between the groups at baseline or account for baseline differences in the analysis. Allocation concealment was the area were most studies showed weakness, with only 2 studies clearly describing the method of randomization and allocation concealment. The total quality score ranged from 6 to 12 (Table 2).

Figure 2 shows that the VAS score for satisfaction of the 4 included studies ranged from a mean difference of 6 , favoring SCD, to a mean difference of -8.8 , favoring CCD. None of the studies reported significant differences. These results were homogenous $\left(I^{2}=0 \%\right)$ and the overall difference was not statistically significant, slightly favoring SCD (mean difference: $=0.896,95 \%$ CI (confidence interval): $-2.947,4.739$ ) (Fig. 2).

Figure 3 shows the differences in impact on quality of life between SCD and CCD reported in 2 studies. In both studies, the difference was not statistically significant. The overall difference slightly favored SCD (mean difference: 0.379), although the difference was not statistically significant (95\% CI: $-0.994,1.751)$ (Fig. 3).

Figure 4 shows that each of the 3 studies assessing the cost difference between the 2 types of dentures reported a lower cost of SCD compared to CCD. When transformed to 2018 USD, the cost of SCD and CCD expressed as mean \pm standard deviation $(S D)$ was $40.64 \pm 10.63$ and $63.35 \pm 16.86$, respectively, in the Brazilian study, ${ }^{18} 844.68$ \pm 47.71 and $1,037.93 \pm 39.23$, respectively, in the Canadian study, ${ }^{4}$ and $350 \pm 35.81$ and $390.23 \pm 38.91$, respectively,

Table 2. Quality assessment of the studies

\begin{tabular}{|c|c|c|c|c|c|c|c|}
\hline Study & $\begin{array}{l}\text { Randomization } \\
\text { and allocation } \\
\text { concealment }\end{array}$ & $\begin{array}{l}\text { Sample size } \\
\text { estimation } \\
\text { method }\end{array}$ & $\begin{array}{l}\text { Inclusion/exclusion } \\
\text { criteria defined }\end{array}$ & $\begin{array}{c}\text { Adequate number } \\
\text { of participants } \\
\text { available at follow-up }\end{array}$ & $\begin{array}{c}\text { Comparability } \\
\text { of groups } \\
\text { at baseline }\end{array}$ & $\begin{array}{l}\text { Outcome } \\
\text { assessors } \\
\text { blinded }\end{array}$ & Total \\
\hline $\begin{array}{l}\text { Regis et al., } 2013^{19} \\
\text { Vecchia et al., } 2014^{18}\end{array}$ & 2 & 2 & 2 & 2 & 2 & 2 & 12 \\
\hline $\begin{array}{l}\text { Kawai et al., } \\
2005,2010,2018^{20,4,10}\end{array}$ & 0 & 2 & 2 & 2 & 2 & 2 & 10 \\
\hline Nuñez et al., $2015^{21}$ & 0 & 2 & 2 & 2 & 2 & 1 & 9 \\
\hline Heydecke et al., $2008^{22}$ & 0 & 0 & 2 & 2 & 0 & 2 & 6 \\
\hline $\begin{array}{l}\text { Jo et al., } 2015^{5} \\
\text { Miyayasu et al., } 2018^{9}\end{array}$ & 0 & 2 & 2 & 0 & 2 & 2 & 8 \\
\hline Ceruti et al., $2017^{6}$ & 0 & 2 & 2 & 0 & 0 & 2 & 6 \\
\hline Lira-Oetiker et al., $2018^{7}$ & 2 & 2 & 2 & 2 & 1 & 2 & 11 \\
\hline
\end{tabular}

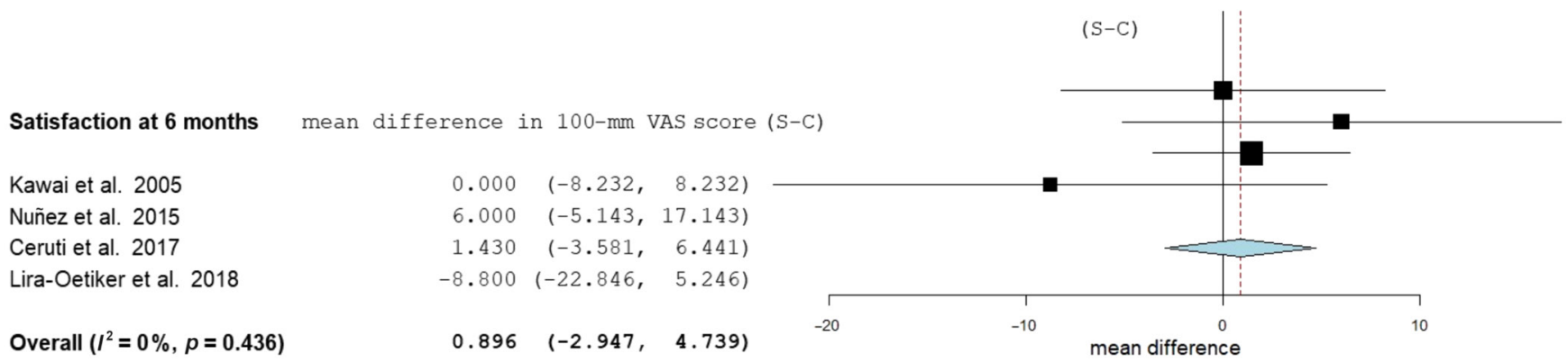

Fig. 2. Forest plot of the meta-analysis of the difference between simplified complete denture (SCD) and conventional complete denture (CCD) in satisfaction at 6 months 
in the Japanese study. ${ }^{9}$ The lowest proportion of cost of SCD to CCD that was reported by Veccia et al. was statistically significant and the absolute cost of the 2 types of dentures was the lowest. ${ }^{18}$ The results of the 3 studies were homogenous $\left(I^{2}=3.1 \%\right)$. The overall estimate indicated a significantly lower cost of SCD as compared to CCD (proportion: 0.740, 95\% CI: 0.597, 0.882) (Fig. 4).

Figure 5 shows that significantly less time was needed for SCD delivery as compared to CCD in the Brazil$\operatorname{ian}^{18}$ and Italian ${ }^{6}$ studies. The results were homogenous $\left(I^{2}=0 \% ; p=0.1\right)$ and the overall estimated difference between the 2 types of dentures was significant (mean difference: -274.16, 95\% CI: -334.17, -199.96), indicating that less time was needed for SCD delivery (Fig. 5).

Figure 6 shows the funnel plot of the studies included in the present meta-analysis. The almost symmetrical distribution of the studies in the plot and the $p$-value of Egger's test of 0.79 indicate that there was no publication bias (Fig. 6).

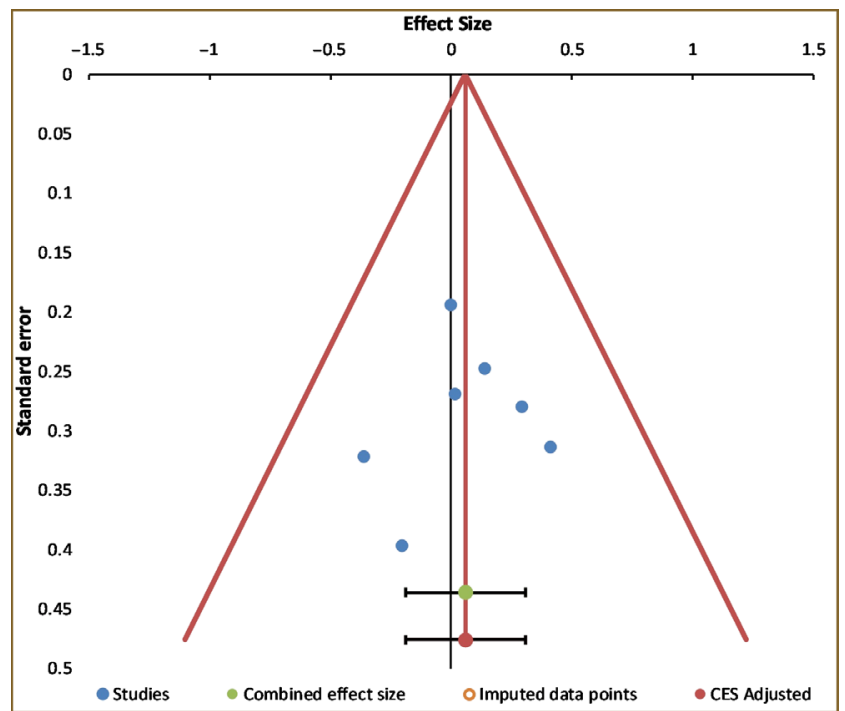

Fig. 6. Funnel plot to assess publication bias CES - combined effect size.
OHIP-19

Regis et al. 2013

Nuñez et al. 2015

Overall $\left(I^{2}=0 \%, p=0.682\right)$
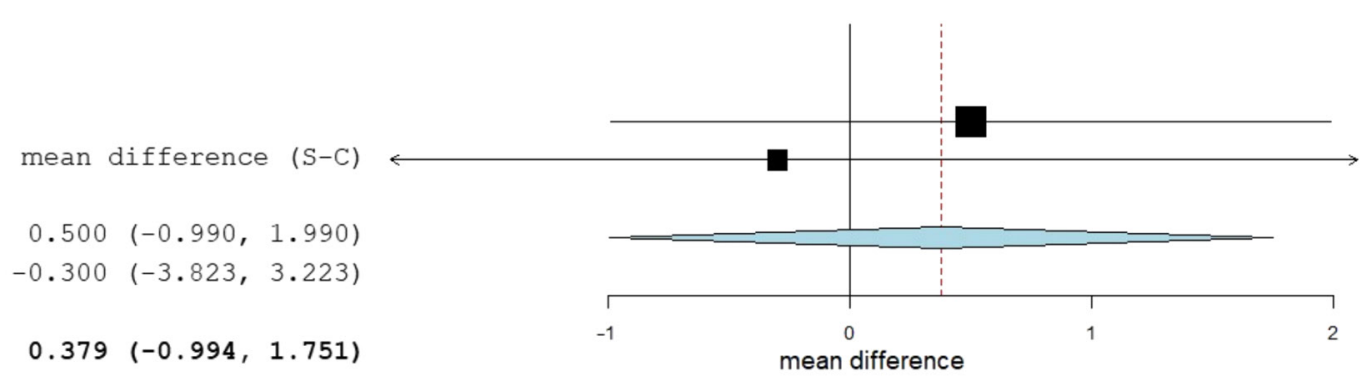

Fig. 3. Forest plot of the meta-analysis of the difference between simplified complete denture (SCD) and conventional complete denture (CCD) in impact on quality of life at 6 months

OHIP-19 - Oral Health Impact Profile-19.

\section{Cost}

Veccia et al. 2013

Kawai et al. 2010

Miyayasu et al. 2018

Overall $\left(I^{2}=3.1 \%, p=0.356\right)$

$P=0.356) \quad 0.740 \quad(0.597,0.882)$

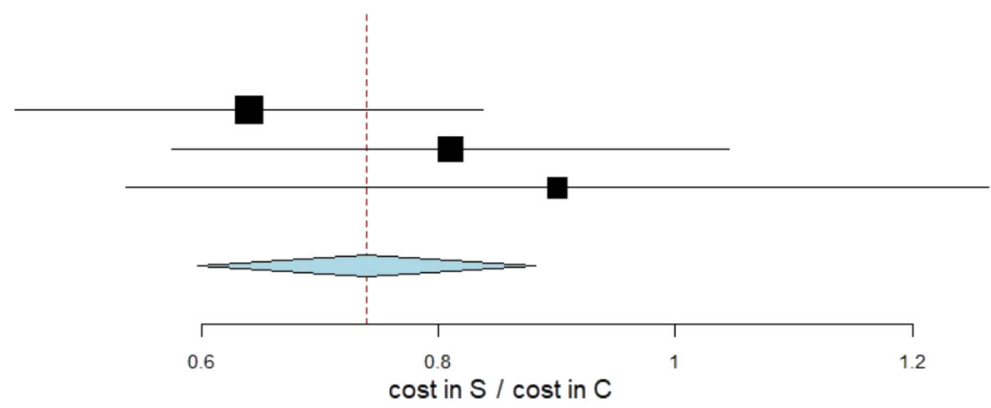

Fig. 4. Forest plot of the meta-analysis of the cost proportion (SCD / CCD)

Time [min]

Vecchia et al. 2013

Ceruti et al. 2017

Overall $\left(I^{2}=0 \%, p=0.10\right)$ mean difference $(\mathrm{S}-\mathrm{C})$

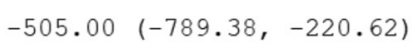

$-274.16(-348.37,-199.96)$

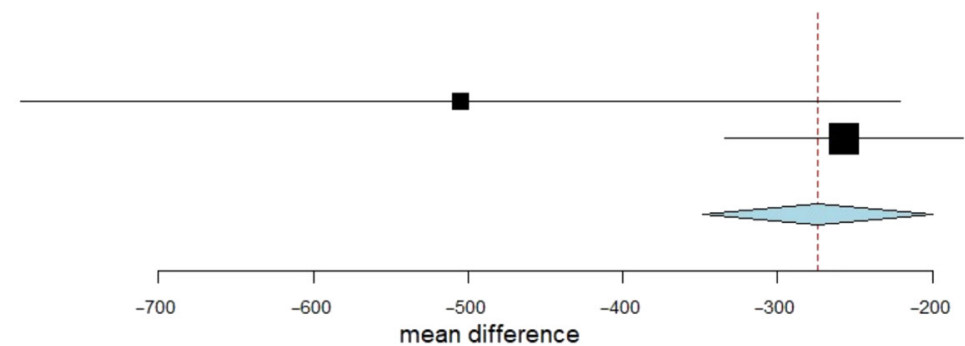

Fig. 5. Forest plot of the meta-analysis of the difference between simplified complete denture (SCD) and conventional complete denture (CCD) in the time needed to deliver the dentures 


\section{Discussion}

The present meta-analysis showed that the 2 types of dentures had a similar impact on quality of life and patient satisfaction. It took significantly less time (about $4.5 \mathrm{~h}(274 \mathrm{~min}))$ to deliver SCD to the patient and the cost of SCD was significantly lower than in the case of CCD (75\% of the cost of CCD). The results of the present metaanalysis are in agreement with the 2 previous systematic reviews, which reported a shorter treatment time, a lower cost, and similar satisfaction and impact on quality of life for SCD in relation to CCD., ${ }^{3,8}$ The present meta-analysis has implications for patients who may be in need of less time-consuming or less costly complete dentures, and may thus benefit from the use of SCD. Our findings also have implications for dental education in the area of complete dentures. It is important to introduce dental students to SCD as an alternative to CCD in indicated cases, since the equality of the 2 types of dentures was demonstrated.

The Canadian study reported the highest absolute cost for both types of dentures. ${ }^{4}$ This may be attributed to health care system characteristics, and is in agreement with a previous study assessing the direct and indirect cost of treating obesity. ${ }^{17}$ In the same study ${ }^{4}$ and also in the Japanese one, ${ }^{9}$ the cost of SCD as compared to CCD was not significantly different. Only in the Brazilian study, where the absolute cost was the lowest for both dentures, was the proportion of cost of SCD to CCD significantly lower. ${ }^{18}$ This indicates that the cost advantage of SCD was more evident in less expensive settings. The cost comparison between the 2 types of dentures forms the basis for recommending that more studies be conducted in lowresource settings to compare the expenditure for both types of dentures and the magnitude of cost reduction in the case of SCD in comparison with CCD.

Both studies evaluating the difference between the 2 dentures in the time needed to deliver the denture to the patient showed statistically significantly less time in the case of SCD. However, Vecchia et al. ${ }^{18}$ reported almost twice as big time difference as Ceruti et al. ${ }^{6}$ This may be explained by the number and type of steps used to fabricate $S C D$ in the 2 studies. Vecchia et al. reported the absence of face bow transfer and the use of a single tryin for the anterior and posterior teeth together. ${ }^{18}$ In the study by Ceruti et al., 3 steps (the definitive impression, the recording of the maxillo-mandibular relationship, and the selection and arrangement of the anterior teeth) were performed during 1 visit, which helped decrease rather the number of visits than the overall time. ${ }^{6}$ This reduced time may be of greater usefulness to elderly patients, who have mobility and/or transportation problems; in their case, fewer visits and less time would be appreciated.

The maximum follow-up in the studies included in this meta-analysis was 6 months, with the exception of 1 study. This is a short time considering how long complete dentures are expected to be used. The similarity in patient satisfaction and impact on quality of life would be expected to change with time. In the single study with a follow-up longer than 6 months, satisfaction and impact on quality of life was assessed also after 10 years. ${ }^{10}$ On a scale ranging from 0 to 120 , the mean OHIP-20 score for SCD was 81.7 and for CCD it was 71.1, with a difference of $10.6 / 120$ or $8.8 \%$, which is greater than the difference in the present study $(0.38 / 38$ or $1 \%)$. Similarly, the same study reported the VAS scores at 6 months of 92 and 91.5 for SCD and CCD, respectively, and the VAS scores after 10 years of 90 and 77.5, accordingly. This may point to a greater difference with time in satisfaction and impact on quality of life, favoring SCD. It is difficult, however, to generalize this conclusion based on a single study.

The present systematic review and meta-analysis has some limitations. It was based on studies having generally small sample sizes and - except for 1 study - short follow-up periods. The current evidence is derived from generally high-resource settings. Future studies are needed in low-resource settings to assess if the cost difference between the 2 types of dentures would still be significant. Such studies are needed before an evidence-based recommendation can be made for the use of SCD regardless of the economic background based on the equality of patient-reported outcomes and a reduced treatment time. The present meta-analysis was based on studies that seem to be free from publication bias, which further bolsters confidence in its findings.

\section{Conclusions}

The present meta-analysis used data from 11 publications reporting on 7 studies conducted in 6 countries. A simplified complete denture was similar to CCD in terms of patient satisfaction and impact on quality of life. It required less time to be delivered in addition to having a lower cost.

\section{ORCID iDs}

Asim Al-Ansari (D) https://orcid.org/0000-0002-0454-801X Maha El Tantawi (D) https://orcid.org/0000-0003-4989-6584

\section{References}

1. Müller F. Interventions for edentate elders - what is the evidence? Gerodontology. 2014;31(Suppl 1):44-51.

2. Carlsson GE, Omar R. The future of complete dentures in oral rehabilitation. A critical review. J Oral Rehabil. 2010;37(2):143-156.

3. Ye Y, Sun J. Simplified complete denture: A systematic review of the literature. J Prosthodont. 2017;26(4):267-274.

4. Kawai Y, Murakami H, Takanashi Y, Lund JP, Feine JS. Efficient resource use in simplified complete denture fabrication. J Prosthodont. 2010;19(7):512-516.

5. Jo A, Kanazawa M, Sato Y, Iwaki M, Akiba N, Minakuchi S. A randomized controlled trial of the different impression methods for the complete denture fabrication: Patient-reported outcomes. J Dent. 2015;43(8):989-996.

6. Ceruti P, Mobilio N, Bellia E, Borracchini A, Catapano S, Gassino G. Simplified edentulous treatment: A multicenter randomized controlled trial to evaluate the timing and clinical outcomes of the technique. J Prosthet Dent. 2017;118(4):462-467. 
7. Lira-Oetiker M, Seguel-Galdames F, Quero-Vallejos I, Uribe SE. Randomised clinical trial of patient satisfaction with traditional and simplified complete dentures. J Oral Rehabil. 2018;45(5):386-392.

8. Paulino MR, Alves LR, Gurgel BC, Calderon PS. Simplified versus traditional techniques for complete denture fabrication: A systematic review. J Prosthet Dent. 2015;113(1):12-16.

9. Miyayasu A, Kanazawa M, Jo A, Sato Y, Minakuchi S. Cost-effectiveness analysis of two impression methods for the fabrication of mandibular complete dentures. J Dent. 2018;68:98-103.

10. Kawai $\mathrm{Y}$, Murakami H, Feine JS. Do traditional techniques produce better conventional complete dentures than simplified techniques? A 10-year follow-up of a randomized clinical trial. J Dent. 2018;74:30-36.

11. Egger E, Smith GD, Altman DG, eds.. Systematic Reviews in Health Care. $2^{\text {nd }}$ ed. London, UK: BMJ Publishing Group; 2001:100-102.

12. Elia M, Normand C, Laviano A, Norman K. A systematic review of the cost and cost effectiveness of using standard oral nutritional supplements in community and care home settings. Clin Nutr. 2016;35(1):125-137.

13. Lansingh VC, Carter MJ, Martens M. Global cost-effectiveness of cataract surgery. Ophthalmology. 2007;114(9):1670-1678.

14. Zhang S, Palazuelos-Munoz S, Balsells EM, Nair H, Chit A, Kyaw MH. Cost of hospital management of Clostridium difficile infection in United States - a meta-analysis and modelling study. BMC Infect Dis. 2016;16(1):447.

15. OpenMeta[Analyst]. http://www.cebm.brown.edu/openmeta/. Accessed November 15, 2018

16. Suurmond R, van Rhee, H, Hak T. Introduction, comparison, and validation of Meta-Essentials: A free and simple tool for meta-analysis. Res Synth Methods. 2017;8(4):537-553.

17. Dee A, Kearns K, O'Neill C, et al. The direct and indirect costs of both overweight and obesity: A systematic review. BMC Res Notes. 2014;7:242.

18. Vecchia MP, Regis RR, Cunha TR, de Andrade IM, da Matta JC, de Souza RF. A randomized trial on simplified and conventional methods for complete denture fabrication: Cost analysis. J Prosthodont. 2014;23(3):182-191.

19. Regis RR, Cunha TR, Della Vecchia MP, Ribeiro AB, Silva-Lovato $C H$, de Souza RF. A randomised trial of a simplified method for complete denture fabrication: Patient perception and quality. J Oral Rehabil. 2013;40(7):535-545.

20. Kawai $Y$, Murakami $H$, Shariati B, et al. Do traditional techniques produce better conventional complete dentures than simplified techniques? J Dent. 2005;33(8):659-668.

21. Nuñez MCO, Silva DC, Barcelos BA, Leles CR. Patient satisfaction and oral health-related quality of life after treatment with traditional and simplified protocols for complete denture construction. Gerodontology. 2015;32(4):247-253.

22. Heydecke G, Vogeler M, Wolkewitz M, Türp JC, Strub JR. Simplified versus comprehensive fabrication of complete dentures: Patient ratings of denture satisfaction from a randomized crossover trial. Quintessence Int. 2008;39(2):107-116. 